\title{
What Does Society Value About Cancer Medicines? A Discrete Choice Experiment in the Belgian Population
}

\author{
Kim Pauwels ${ }^{1} \cdot$ Isabelle Huys $^{1}$ (D) $\cdot$ Minne Casteels $^{1} \cdot$ Yvonne Denier $^{2} \cdot$ Martina Vandebroek $^{3}$ (D) $\cdot$ Steven Simoens $^{1}$ (C)
}

Published online: 30 July 2019

(c) The Author(s) 2019

\begin{abstract}
Background Debate on pricing and reimbursement of cancer medicines highlights the need to establish the value of cancer medicines.

Objective This study aims to elicit the trade-offs in cancer medicine characteristics that the Belgian population is willing to make.

Methods A discrete choice experiment used six attributes with three levels each, based on literature and focus group discussions. The survey was sent to a random sample of 3500 Belgian citizens. Based on the choice of 961 respondents, individual parameters were estimated with a mixed logit model.

Results Societal value of cancer medicines was positively affected by a higher number of patients eligible for treatment, a high initial life expectancy and quality of life of patients, a high gain in quality of life and life expectancy due to treatment, and a low treatment cost. The value of 1-year gain in life expectancy was independent from the initial life expectancy of the patient. However, the value of one-point gain in quality of life was higher for patients with a low initial quality of life than for patients with a high initial quality of life.

Conclusions This study has shown that gain in quality of life with cancer medicines is valued higher by Belgian society for patients who have lower initial quality of life before the start of treatment.
\end{abstract}

\section{Key Points for Decision Makers}

This study provided evidence about the way in which the Belgian population makes trade-offs between characteristics of new cancer medicines.

The value of an increase in quality of life was higher for patients who have a low quality of life before treatment.

Trade-offs between quality of life and life expectancy is depended on the patient's initial quality of life.

Steven Simoens

steven.simoens@kuleuven.be

1 Department of Pharmaceutical and Pharmacological

Sciences, KU Leuven, P.O. Box 521, Onderwijs en

Navorsing 2, Herestraat 49, 3000 Leuven, Belgium

2 Department of Public Health and Primary Care, KU Leuven, 3000 Leuven, Belgium

3 Faculty of Economics and Business, KU Leuven, 3000 Leuven, Belgium

\section{Introduction}

Being the number one therapeutic area for global spending on medicines, cancer is identified as a major driver for increased spending on medicines, and this trend is expected to continue in the future [1-4]. While the number of available treatments, cancer incidence, demographics and diagnostics account for rising utilization, there is pressure on cancer medicine prices [5]. However, list prices of cancer medicines do not account for confidential discounts in many countries, jeopardizing transparency about pricing both within and between countries [6,7].

Given that financial resources are constrained, health authorities need to prioritize the most valuable medicines. Furthermore, rejection of reimbursement of cancer medicines based on prices that outweigh the benefits often evokes societal debate. Therefore, national health authorities tend to make exemptions from cost-saving or benefit-maximizing measures in order to enable patient access to newly launched cancer medicines that would otherwise not reach the market due to their price [8]. Even though such exemptions may be justified by a societal preference for access to cancer 
medicines, a systematic literature review found inconsistent results relating to cancer preferences [9].

The struggle that national health authorities face during price setting and reimbursement of cancer medicines highlights the need to establish the value of cancer medicines [10]. Furthermore, the relevance of outcomes and endpoints in clinical trials for cancer is currently debated by regulators, payers and clinicians [11], making it hard to define what can be considered a valuable cancer medicine. While price is often related to the price of competitors and to what society is able to bear [5], value refers to the intrinsic appreciation of the medicine. Different perspectives on value hold, but in light of efficient resource allocation within a social health insurance system, payers need to take account of societal preferences.

Previous research on societal preferences for resource allocation in health care has identified multiple criteria for priority setting, but also showed that results are heterogeneous and are likely to be context-specific and dependent on the elicitation method [12-14]. Focusing on priority setting in cancer care, a literature review indicated that results vary between types of respondents [15]. The aim of this study is to quantify trade-offs in cancer medicine characteristics that the Belgian population is willing to make.

\section{Methods}

\subsection{Selection of Attributes and Levels}

The databases Medline and Embase were searched in December 2014, for evidence about preferences for resource allocation published in English over the last 20 years. The search terms used were "preferences" or "value" or "choice" and "priority" or "resource allocation". Additionally, a study performed on societal preferences for resource allocation in health care, performed by the Belgian Health Care Knowledge Centre in 2014, was taken into account [12]. Societal preferences for resource allocation in general have been investigated, but no such study specific for cancer medicines was found. Based on a search of 13 relevant articles, a list of nine attributes that are potentially involved in societal valuation of cancer medicines was made. Three focus group discussions (FGDs) with six participants each were conducted in February 2015 with a view to make a further selection of attributes relevant for valuation of cancer medicines, and to identify wording that is understandable to lay persons. Participants for FGD were recruited through flyers distributed in the University Hospitals Leuven and social media.

FGDs were conducted according to the recommendations by Krueger and Casey [16]. The FGD started with a short introduction by all participants. An introductory question asked about their thoughts and feelings that are evoked when talking about cancer. Next, the aim and course of the FGD was explained and the topic of budgetary constraints and resource allocation was introduced. First, three statements based on ethical principles (equity, health-maximization and rule of rescue) were presented to start an introductory discussion. Then, three hypothetical scenarios were presented to ask about characteristics of (A) a patient, (B) a disease or (C) a medicine that participants would use to prioritize if there is only money to treat one (A) patient, (B) disease or (C) use one medicine. FGDs were led by one researcher, video and audio recorded, verbatim transcribed and analyzed using thematic framework analysis. All transcripts were analyzed anonymously. Participants received a compensation of $€ 20$. FGDs were repeated until data saturation.

Results of the FGD are described elsewhere [17]. Six attributes with three levels each were defined, including the possibility to set levels in a quantitative manner, the relevance of the individual levels, and plausibility of the combinations of levels that are related to each other. Attributes describing behavior or personal characteristics of a patient, not specific to a medicine or the disease that the medicine will treat, were excluded. For the cost attribute, levels needed to be of a certain burden on the one hand, and mutually distinguishable on the other hand. Given that cancer medicines are in general liable to third-party payment by the social health insurance system in Belgium, the absolute price or budgetary impact of cancer medicines was assumed to be irrelevant for the majority of citizens. Therefore, the cost attribute was defined as the additional tax per year that every taxpayer needs to pay to cover the reimbursement of the medicine. Assuming that people are not aware of the taxes retained from income, the levels were chosen based on the yearly compulsory contribution that is directly paid to the health insurance fund by each Belgian citizen. Attributes and attribute levels (levels were subsequently recoded to facilitate interpretation) are presented in Table 1.

\subsection{Survey Design}

Six attributes with 3 levels each result in a full factorial design of 729 scenarios that was reduced to a fractional factorial design of 4 blocks consisting of 10 pairwise choicesets each, taking into account D-efficiency and avoiding duplicates and dominant alternatives. Six main effects and two interaction effects were estimated. Prior information concerning people's preferences was considered with a view to organize attribute levels from low to high priority. For each block of choice sets, a survey was designed, resulting in four versions of the survey, differing in attribute levels. The survey asked respondents to choose between two hypothetical cancer medicines, if only one of them can be 
Table 1 Attributes and attribute levels for the discrete choice experiment

\begin{tabular}{|c|c|c|c|}
\hline & Attribute & Levels & Coding \\
\hline \multirow[t]{3}{*}{$X 1$} & Number of patients & 1000 & 1 \\
\hline & Number of patients eligible for treatment with the medicine & 5000 & 5 \\
\hline & & 10,000 & 10 \\
\hline \multirow[t]{3}{*}{$X 2$} & Initial life expectancy & 6 months & 1 \\
\hline & Life expectancy of the patient who is eligible for treatment with the medicine. Life expectancy & 2 year & 4 \\
\hline & before treatment & 10 year & 20 \\
\hline \multirow[t]{3}{*}{$X 3$} & Initial quality of life & $2 / 10$ & 2 \\
\hline & Quality of life of the patient who is eligible for treatment with the medicine. Quality of life & $4 / 10$ & 4 \\
\hline & before the treatment & $6 / 10$ & 6 \\
\hline \multirow[t]{3}{*}{$X 4$} & Gain in life expectancy & No gain & 0 \\
\hline & Gain in life expectancy due to the treatment & 2 years & 2 \\
\hline & & 5 years & 5 \\
\hline \multirow[t]{3}{*}{$X 5$} & Gain in quality of life & No gain & 0 \\
\hline & Gain in quality of life due to the treatment & $2 / 10$ & 2 \\
\hline & & $4 / 10$ & 4 \\
\hline \multirow[t]{3}{*}{$X 6$} & Cost & $€ 20 /$ year & 2 \\
\hline & Extra tax per year that every taxpayer needs to pay to cover the costs of the treatment & $€ 40 /$ year & 4 \\
\hline & & $€ 60 /$ year & 6 \\
\hline
\end{tabular}

Continuous coding was applied for the statistical analysis

reimbursed by the social health insurance system (an example of a choice set included in the survey is presented in Fig. 1). Additional information on each of the attributes was provided. Respondents were asked about their sex, year of birth, highest level of education, income group and whether they had been diagnosed with cancer previously. The survey was provided to the sample respondents by paper or online through Limesurvey.

\subsection{Sampling and Correspondence}

The survey was pre-tested in a group of 15 randomly selected visitors to the University Hospitals Leuven. This pre-test provided validation of the survey in terms of clarity of presentation and survey instructions, task difficulty and length of the survey. Sampling and correspondence were conducted by the Federal Public Office Internal Affairs in agreement with the Belgian Privacy legislation. A random sample was drawn from the Belgian National Registry of patients aged between 19 and 80 years, with a view to extracting a sample that is representative of the Belgian population. Distribution of age and place of residence (region) were predefined. The pilot survey was sent to a sample of 250 individuals in the Dutchspeaking community of Belgium. The main survey was sent to a sample of 3500 individuals in the Dutch-speaking and French-speaking community in Belgium, excluding the German community due to language barriers. The researchers had no access to sample information. Each respondent was anonymously allocated to a response code and linked to one of the four blocks. On day one, the sample was invited to participate in the online survey for which a web link was provided. The invitation letter started with an introduction, emphasizing the burden of cancer medicines on the public health-care budget and the trade-offs that policy makers need to make to allocate the scarce health-care budget. Respondents were required to fill in the respondent code before they could start the survey. After seven days, a reminder postcard including the web link and respondents code was sent to the complete sample. After 21 days, a second reminder was sent to non-responders, including the paper version of the survey and a stamped envelope to return the completed questionnaire. The invitation for the final survey was sent on October 7th, 2015 and data collection was closed on December 1st, 2015.

\subsection{Analysis}

Respondents for whom an invariable or alternating pattern was observed in the answers were excluded. First, a conditional logit model was estimated using SAS 9.4 yielding the preferences of an average person. Attributes were selected based on 0.05 significance level. Furthermore, a mixed logit model was estimated using the R-package bayesm to get individual preference parameters. In this model, the utility that person $n$ gets from alternative $j$ in choice set s was assumed to be:

$U_{n j s}=\beta_{n} X_{n j s}+\varepsilon_{n j s}$, 
Two new medicines to treat cancer enter the market. Which of both medicines is most valuable according to you? All characteristics that are not described, are the same for both medicines. Even when none of these medicines is good according to your opinion, you can indicate the medicine that is the most valuable one from the two. We want to know your opinion, there is no right or wrong. You can find additional information on the characteristics below.

\begin{tabular}{|c|c|c|}
\hline & Medicine A & Medicine B \\
\hline Number of patients that is eligible for treatment with the medicine & 5000 patients & 1000 patients \\
\hline Time until the patient dies (=life expectancy) when the patient will not be treated with the medicine & 10 year & 2 year \\
\hline Number of years of life that the patient can gain due to the medicine & +2 year & +5 year \\
\hline Quality of life of the patient when the patient will be not treated with the medicine & $2 / 10$ & $6 / 10$ \\
\hline Quality of life that the patient can gain due to the medicine & $+0 / 10$ & $+2 / 10$ \\
\hline Additional tax that every taxpayer needs to pay when the medicine will be reimbursed & $€ 60$ per year & $€ 40$ per year \\
\hline Indicate the medicine that is most valuable according to you & & \\
\hline
\end{tabular}

Explanation of the characteristics

Number of patients: the number of patients that is eligible for treatment with the new medicine

Time until the patient dies (=life expectancy) when the patient will not be treated with the medicine: number of months or years that the patient will live when he will not be treated with the new medicine. Life expectancy of a patient with a disease that is eligible for treatment with a new medicine, but not (yet) treated with the new medicine.

Number of years of life that the patient can gain due to the medicine: number of life years that the new treatment yields. The effect of the new treatment on the time until the patient dies. These years of life adds to the life expectancy that the patient has when he is not treated with the new medicine.

Quality of life of the patient when the patient will be not treated with the medicine: quality of life of a patient with a disease that is eligible for treatment with the new medicine, but is not (yet) treated with the new medicine. This quality of life involves for example the mobility, autonomy, daily activities, pain and mood of the patients. This is expressed on a 10-point scale. A score of 10/10 mean that the patient had a perfect quality of life. The higher the score, the better the quality of life of the patient.

Quality of life that the pain can gain due to the medicine: the number of points that the patients wins in quality of life due to the new medicine. The gain in quality of life due to the new medicine. This gain in quality of life adds to the quality of life that the bpatient has when he is not treated with the new medicine.

Additional tax that every taxpayer needs to pay when the medicine will be reimbursed; the money that is used by the health insurance funds to pay the medicines, comes from taxes that citizens like you pay. The extra amount of money that every taxpayer in Belgian needs to pay yearly, additional to current taxes, in order to cover the costs of the new medicine.

Fig. 1 Example of a choice set included in the discrete choice experiment

where $X_{n j s}$ has the values of the $p$ attributes that relate to the alternative $j$ in choice set $s$ of decision maker $n$. $\beta_{n}$ is a $p$-dimensional vector of parameters representing the values that person $\mathrm{n}$ attaches to the $p$ variables. The random terms $\varepsilon_{n j s}$ were assumed to be independently and identically extreme value distributed and for the $i$ th element of $\beta_{n}(i=1 \ldots p)$ we assumed a normal distribution $N\left(\mu_{i} ; \sigma_{i}^{2}\right)$.

Willingness to pay (WTP), i.e. marginal rate of substitution, was calculated by the negative ratio of the average estimate of attribute $\mathrm{i}$ and the average estimate for price $\left(-\mu_{i} / \mu_{\text {price }}\right)$, taking into account interaction terms where appropriate. Post-hoc comparison with the attributes dummy coded gave a slightly better fit (pseudo $R^{2}=0.1839$ ) [18] than the model with linear effects of the attributes, but we report the latter model because the former would complicate the interpretation of WTP considerably.

Characteristics of respondents were analyzed using descriptive statistics in MS Excel. The influence of these respondent characteristics on the individual estimates from the mixed logit model was further tested using linear regression with backward selection based on 0.05 significance level.

\section{Results}

\subsection{Sampling}

A response rate of 30.7\% (1074/3500) was obtained. Based on validity of responses and excluding questionnaires that had not been fully completed, 961 respondents were retained in the final analysis. Fifty-seven percent (546/961) of these respondents completed the questionnaire online, while the remaining 43\% (414/961) of respondents completed the survey on paper.

Descriptive statistics of the sample are presented in Table 2. Based on data from Statistics Belgium [19] and from Eurostat [20], the group of respondents resembled the Belgian population. On 1st January 2015, 50.89\% of the Belgian population was female and $49.11 \%$ was male. In 2014, $15.7 \%$ of the population (aged over 15) were educated in primary school, $55 \%$ were educated in secondary school, and $29.6 \%$ had received higher education. The average net household income per month was $€ 1333$ in 2011 . The median age of the Belgian population in 2014 was 41.2. Three percent of the population was alive after being diagnosed with cancer between 2004 and 2014. However, the group of Frenchspeaking participants was underrepresented compared to the group of Dutch-speaking participants. Therefore, to check 
Table 2 Descriptive statistics for respondents of discrete choice experiment $(n=961)$

\begin{tabular}{|c|c|c|}
\hline & $N$ & $\%$ \\
\hline \multicolumn{3}{|l|}{ Gender } \\
\hline Female & 472 & 49.2 \\
\hline Male & 438 & 45.6 \\
\hline Missing & 50 & 5.2 \\
\hline Age (2015) & \multicolumn{2}{|c|}{$\begin{array}{l}\text { Average } 47.94(19-80, \text { SD } \\
15.50, n=910)\end{array}$} \\
\hline \multicolumn{3}{|l|}{ Language } \\
\hline Dutch & 728 & 75.8 \\
\hline French & 232 & 24.2 \\
\hline \multicolumn{3}{|l|}{ Highest level of education } \\
\hline Primary school & 89 & 9.3 \\
\hline Secondary school & 397 & 41.1 \\
\hline Higher education & 417 & 43.4 \\
\hline Missing & 57 & 5.9 \\
\hline \multicolumn{3}{|l|}{ Net household income per month } \\
\hline Less than $€ 1000 /$ month & 63 & 6.6 \\
\hline$€ 1000 /$ month- $€ 2500 /$ month & 392 & 40.8 \\
\hline$€ 2500 /$ month-€4500/month & 372 & 38.8 \\
\hline More than $€ 4500 /$ month & 75 & 7.8 \\
\hline Missing & 58 & 6.0 \\
\hline \multicolumn{3}{|l|}{ Diagnosed with cancer } \\
\hline Yes & 66 & 6.9 \\
\hline No & 843 & 87.8 \\
\hline Missing & 51 & 5.3 \\
\hline
\end{tabular}

for potential language effects, we included interaction terms between all six explanatory variables and a dummy representing the different languages in the conditional logit model to allow for different parameters for the Dutch- and Frenchspeaking respondents. None of these interaction terms were significant (with $p$-values between 0.24 and 0.97 ), which indicated that different language groups are not different when assessing the relative value of an attribute level.

\subsection{Modelling}

The estimated mean in the mixed logit model (log likelihood value: -5133.4 ) was found to be similar (correlation $=0.99$ ) to the estimates for the preference of an average person in the conditional logit model (log likelihood value: -5199.8 ), which demonstrated that the results are robust. The conditional logit model (see Table 3) showed that all attributes significantly influence the value of a cancer medicine for an average person (pseudo $R^{2}=0.1739$ ) [18]. Except for the cost-related attribute, people assigned higher value to the treatment when the attribute level is higher (Table 3). For instance, if the number of patients increases by 1000 , then the value of treatment rises by 0.067 . We tested for all interactions between attributes but reported significant interactions only in Table 3.

No significant interaction was found between initial life expectancy and gain in life expectancy. In other words, the value of 1-year gain in life expectancy was independent of the initial life expectancy of the patient. Based on price levels set in the survey design, the marginal WTP for 1-year gain in life expectancy was $€ 3.55\left(-\mu_{4} / \mu_{6}\right)$, irrespective of the initial life expectancy of the patient.

The interaction between initial quality of life and gain in quality of life was significant and had a negative sign (Table 3). This means that one-unit gain in quality of life was worth more for patients with lower initial quality of life than for patients with higher initial quality of life. For instance, the WTP for one-unit gain in quality of life was $64 \%$ larger for a patient with an initial quality of life of $2 / 10$ than for someone with an initial quality of life of 6/10.

With respect to the trade-off between gain in quality of life (which depends on initial quality of life) and gain in life expectancy, the value of 1-year gain in life expectancy ( $€ 3.55$ in terms of WTP) was equal to a one-point increase in quality of life for a patient with an initial quality of life of $4 / 10$. When the initial quality of life of the patient was higher than 4/10, one-point gain in quality of life was worth less than 1-year gain in life expectancy. When the initial quality of life of the patient was lower than 4/10, one-point

Table 3 Average of individual parameters of estimates for discrete choice experiment

\begin{tabular}{|c|c|c|c|c|c|c|c|}
\hline & & \multicolumn{2}{|l|}{ Conditional logit } & \multicolumn{4}{|l|}{ Mixed logit } \\
\hline & & $\beta(\mathrm{SE})$ & $p$ value & $\mu(\mathrm{SE})$ & $p$ value & $\sigma(\mathrm{SE})$ & $p$ value \\
\hline$X 1$ & Number of patients & $0.0647(0.0071)$ & $<0.0001$ & $0.0878(0.0108)$ & 0.0702 & $0.1175(0.0103)$ & $<0.0001$ \\
\hline$X 2$ & Initial life expectancy & $0.0104(0.0031)$ & $<0.0001$ & $0.0095(0.0053)$ & $<0.0001$ & $0.0896(0.0051)$ & $<0.0001$ \\
\hline$X 3$ & Initial quality of life & $0.1382(0.0205)$ & $<0.0001$ & $0.2178(0.0301)$ & $<0.0001$ & $0.2187(0.0329)$ & $<0.0001$ \\
\hline$X 4$ & Gain in life expectancy & $0.3265(0.0141)$ & $<0.0001$ & $0.5001(0.0245)$ & $<0.0001$ & $0.2669(0.0244)$ & $<0.0001$ \\
\hline$X 5$ & Gain in quality of life & $0.5034(0.0304)$ & $<0.0001$ & $0.7606(0.0461)$ & $<0.0001$ & $0.3676(0.0260)$ & $<0.0001$ \\
\hline$X 6$ & Cost & $-0.1103(0.0148)$ & $<0.0001$ & $-0.1771(0.0222)$ & $<0.0001$ & $0.2359(0.0229)$ & $<0.0001$ \\
\hline$X 3 \times X 5$ & Quality $\times$ gain quality & $-0.0410(0.0059)$ & $<0.0001$ & $-0.0635(0.0081)$ & $<0.0001$ & $0.0128(0.0142)$ & 0.3705 \\
\hline
\end{tabular}


gain in quality of life was worth more than 1-year gain in life expectancy.

Average preferences were not significantly different for males and females, but a significant difference was observed between respondents who completed the online survey and respondents who completed the paper version of the survey: respondents who completed the online survey attached a lower value to initial life expectancy, but attached a higher value to the number of patients, gain in life expectancy, and gain in quality of life.

Individual estimates for the preference related to gain in quality of life based on the mixed logit model correlated positively with the educational level of the respondents, indicating that respondents with the lowest educational level (primary school only) attach less value to gain in quality of life compared to higher educated respondents (correlation $=0.101, p=0.002$ ). A significant positive correlation between individual estimates related to initial life expectancy and the age of the respondents indicated that older respondents assign more value to initial life expectancy than younger respondents (correlation $=0.122, p<0.005$ ).

\section{Discussion}

The expanding number of cancer patients and emerging therapeutic options with escalating costs require priority setting in resource allocation for cancer medicines. Empirical evidence on societal preferences allows to set priorities in an informed way. A high number of patients eligible for treatment, a high initial life expectancy and quality of life of patients eligible for treatment, a high gain in quality of life and life expectancy, and a low cost are preferred for cancer medicines by the general society in Belgium.

While a preference for larger health gains was also observed in other studies $[12,13,15,21]$, to the best of the authors' knowledge, this is the first study demonstrating the effect of a patient's initial quality of life on how society weighs gain in quality of life. The preference for gain in quality of life decreases when the initial quality of life is higher. This is in line with diminishing preferences for health gains as the size of health gain increases [13, 22]. The fact that gain in quality of life is of higher value for patients who have lower initial quality of life before the start of the treatment, suggests that society prefers to obtain a minimum quality of life for all patients [13, 22].

The assessment of quality of life will however require input from the patient. Patient involvement in decision making at several levels of the medicine lifecycle nowadays is increasingly enabled through collaborative research projects between industry and academics. At regulatory level, patient reported outcomes (PRO), including healthrelated quality of life (HRQL), were put under scrutiny by the Oncology Working Party at the European Medicines Agency (EMA) [23]. Until today, appreciation of HRQL within cancer trials is mainly limited to late line therapies and palliative settings and therefore, the number of clinical trials measuring quality of life for cancer medicines is low [24]. By April 2016, an appendix on the use of PRO was added to the EMA guideline on the evaluation of anticancer medicines and recognized that clinically important information can be missed by solely considering outcomes related to survival or anti-tumor activity [25]. With the prospect of PRO and HRQL consideration in the approval of a cancer medicine at regulatory level, payers also need to prepare to take PRO and HRQL into account. For instance, debate continues in the literature whether the EuroQol five-dimension scale (EQ-5D) captures the most relevant outcomes for cancer patients [26, 27].

Based on societal preferences as revealed in our study, specific unmet needs in terms of quality of life and life expectancy can be defined by considering the initial health state of the patient under the standard treatment. The development of valuable cancer medicines can be incentivized when premium price setting and reimbursement distinguish between those medicines that meet these needs and those that offer less relevant health benefits.

This study is limited to generic attributes that characterize a medicine, its effect or the disease that it intends to treat. Attributes are not specific to cancer; but applying the experimental setting to cancer medicines provides a context recognized by lay persons because cancer is a disease of all social and demographic classes in the population.

No conclusions on the external or internal validity of our results can be drawn. First, the choice of attributes and their levels, the selection of choice sets, and framing effects may influence results [28]. Second, we assume that participants consider all attributes and all levels during the choice task, while research has shown that ignorance of particular attributes or levels can occur and can lead to bias [29, 30]. Although our model does not account for complex choice behavior, the selection of attributes and design of survey is based on empirical research and extensive piloting to ensure cognitive burden and understanding of choice behavior. Finally, choice elicitation techniques other than a discrete choice experiment exist and can lead to other results.

Acknowledgements The authors would like to express their gratitude to the survey participants.

Author Contributions SS came up with the concept for this study. KP set up the study and collected the data. KP and MV analyzed the data. All authors contributed to the follow-up of the study and the interpretation of the data, and critically reviewed the manuscript. SS acts as the overall guarantor of this study. 


\section{Compliance with Ethical Standards}

Funding This study was funded by the Research Foundation Flanders and Flanders Innovation \& Entrepreneurship.

Conflict of interest $\mathrm{KP}, \mathrm{IH}, \mathrm{MC}, \mathrm{YD}, \mathrm{MV}$ and SS have no conflicts of interest that are relevant to this manuscript.

Ethical approval The study protocol was approved by the Belgian Privacy Commission (Sectoraal comité van het Rijksregister) on February 18th, 2015. As only anonymous data were used, approval of the study by the Ethics Committee was not required.

Informed consent All participants provided written informed consent to participate in the focus group discussions.

Data availability statement The datasets generated during and/or analyzed during the current study are available from the corresponding author on reasonable request.

Open Access This article is distributed under the terms of the Creative Commons Attribution-NonCommercial 4.0 International License (http://creativecommons.org/licenses/by-nc/4.0/), which permits any noncommercial use, distribution, and reproduction in any medium, provided you give appropriate credit to the original author(s) and the source, provide a link to the Creative Commons license, and indicate if changes were made.

\section{References}

1. Berggren R, Moller M, Moss R, Poda P, Smietana K. Outlook for the next 5 years in drug innovation. Nat Rev Drug Discov. 2012;11:435-6.

2. IMS Institute for Healthcare Informatics. The global use of medicines: outlook through 2016. IMS Institute for Healthcare Informatics. 2012. http://www.imshealth.com/portal/site/ims/.

3. Organisation for Economic Co-operation and Development (OECD). Focus on Health Spending. Paris: OECD; 2015. http:// www.oecd.org/health/health-systems/Focus-Health-Spending2015.pdf.

4. Luengo-Fernandez R, Leal J, Gray A, Sullivan R. Economic burden of cancer across the European Union: a population-based cost analysis. Lancet Oncol. 2013;14:1165-74.

5. Sullivan R, et al. Delivering affordable cancer care in high-income countries. Lancet Oncol. 2011;12:933-80.

6. van Harten WH, Wind A, de Paoli P, Saghatchian M, Oberst S. Actual costs of cancer drugs in 15 European countries. Lancet Oncol. 2016;17:18-20.

7. Vogler S, Vitry A, Babar ZU. Cancer drugs in 16 European countries, Australia, and New Zealand: a cross-country price comparison study. Lancet Oncol. 2016;17:39-47.

8. Pauwels K, Huys I, Casteels M, De Nys K, Simoens S. Market access of cancer drugs in European countries: improving resource allocation. Target Oncol. 2014;9:95-110.

9. Morrell L, Wordsworth S, Rees S, Barker R. Does the public prefer health gain for cancer patients? A systematic review of public views on cancer and its characteristics. PharmacoEconomics. 2017;35:793-804.

10. Fojo T, Lo AW. Price, value, and the cost of cancer drugs. Lancet Oncol. 2016;17:3-5.
11. Wilson MK, Karakasis K, Oza AM. Outcomes and endpoints in trials of cancer treatment: the past, present, and future. Lancet Oncol. 2015;16:e32-42.

12. Cleemput I, et al. Incorporating societal preferences in reimbursement decisions-relative importance of decision criteria according to Belgian citizens. Brussels: Belgian Healthcare Knowledge Centre; 2014. https://kce.fgov.be/sites/default/files /page_documents/KCE_234_reimbursement_decisions_Repor t_0.pdf.

13. Gu Y, Lancsar E, Ghijben P, Butler JR, Donaldson C. Attributes and weights in health care priority setting: a systematic review of what counts and to what extent. Soc Sci Med. 2015;146:41-52.

14. Whitty JA, Lancsar E, Rixon K, Golenko X, Ratcliffe J. A systematic review of stated preference studies reporting public preferences for healthcare priority setting. Patient. 2014;7:365-86.

15. MacLeod TE, Harris AH, Mahal A. Stated and revealed preferences for funding new high-cost cancer drugs: a critical review of the evidence from patients, the public and payers. Patient. 2016;9:201-22.

16. Krueger RA, Casey MA. Focus groups. A practical guide for applied research. Thousand Oaks: Sage Publications, Inc.; 2000.

17. Pauwels K, Huys I, Casteels M, Simoens S. Qualitative assessment of societal preferences for market access of cancer drugs. Value Health. 2015;18:A486.

18. McFadden D. Quantitative methods for analyzing travel behaviour on individuals: some recent developments. In: Hensher D, Stopher P, editors. Behavioural travel modelling. London: Croom Helm; 1978. p. 279-318.

19. Statistics Belgium. Structure of the population. https://statb el.fgov.be/en/themes/population/structure-population.

20. Eurostat. https://ec.europa.eu/eurostat/home?p_auth=BMAau Wo7\&p_p_id=estatse. 21 .

21. Bryan S, Roberts T, Heginbotham C, McCallum A. QALY-maximisation and public preferences: results from a general population survey. Health Econ. 2002;11:679-93.

22. Rowen D, et al. Eliciting societal preferences for weighting QALYs for burden of illness and end of life. Med Decis Making. 2016;36:210-22.

23. European Medicines Agency. Reflection paper on the use of patient reported outcome (PRO) measures in oncology studies. London: European Medicines Agency; 2014.

24. Beauchemin C, Lapierre ME, Letarte N, Yelle L, Lachaine J. Use of intermediate endpoints in the economic evaluation of new treatments for advanced cancer and methods adopted when suitable overall survival data are not available. Pharmacoeconomics. 2016;34:889-900.

25. European Medicines Agency. Appendix 2 to the guideline on the evaluation of anticancer medicinal products in man - the use of patient-reported outcome (PRO) measures in oncology studies. https://www.ema.europa.eu/en/appendix-2-guideline-evaluation -anticancer-medicinal-products-man-use-patient-reported-outco me-pro.

26. Tordrup D, Mossman J, Kanavos P. Responsiveness of the EQ-5D to clinical change: is the patient experience adequately represented? Int J Technol Assess Health Care. 2014;30:10-9.

27. Longworth L, Yang Y, Young T, Mulhern B, Hernández Alava $\mathrm{M}$, Mukuria C. Use of generic and condition-specific measures of health related quality of life in NICE decision-making: systematic review, statistical modeling and survey. Health Technol Assess. 2014;18(9):1-254.

28. Howard K, Salkeld G. Does attribute framing in discrete choice experiments influence willingness to pay? Results from a discrete choice experiment in screening for colorectal cancer. Value Health. 2009;12:354-63. 
29. Erdem S, Campbell D, Thompson C. Elimination and selection by aspects in health choice experiments: prioritising health service innovations. J Health Econ. 2014;38:10-22.
30. Erdem S, Campbell D, Hole AR. Accounting for attribute-level non-attendance in a health choice experiment: does it matter? Health Econ. 2015;24:773-89. 